\title{
Merancang Sistem Informasi Pendaftaran Nikah Pada KUA dengan Object Oriented Methodology
}

\author{
Sri Rahayu ${ }^{1}$, Gilang Kartika Hanum Ramadhan ${ }^{2}$, Khairun Nisa Nabila ${ }^{3}$ \\ Dosen AMIK RAHARJA Tangerang', Dosen STMIK RAHARJA Tangerang ${ }^{2}$, \\ Mahasiswa STMIK RAHARJA Tangerang ${ }^{3}$ \\ Jl. Jendral Sudirman no.40, Modern, Cikokol Tangerang ${ }^{1,2}$ \\ Email : srirahayu@ raharja.info' ${ }^{1}$ tuti@raharja.info ${ }^{2}$, khairun.nabila@raharja.info ${ }^{3}$
}

\begin{abstract}
ABSTRAK
KUA (Kantor Urusan Agama) Kecamatan Rajeg sudah memiliki website, tetapi KUA tersebut belum menggunakan sistem informasi yang secara khusus menangani data pendaftaran persyaratan nikah di KUA. Aktivitas penginputan data dan pengolahan data masih menggunakan sistem manual. Sistem tersebut berjalan tidak optimal karena kompleksitas pada prosesnya, mulai dari pengisian data diformulir pendaftaran oleh calon mempelai dibuku, proses pengolahan berkas-berkas pendaftaran, sampai dengan proses untuk menghasilkan laporan. Hambatan atau kendala saat pembuatan laporan terjadi karena berkas tidak tersimpan di satu bagian saja, akibatnya pihak administrasi mengalami keterlambatan dan mengalami kesalahan saat pembuatan laporan karena berkas yang tersebar. Setelah meneliti dan menganalisa permasalahan yang ada dalam sistem saat ini, user pada KUA perlu difasilitasi sebuah sistem informasi pendaftaran persyaratan nikah berbasis web untuk mempermudah calon mempelai untuk memperoleh informasi dan pendaftaran nikah, maupun pihak adminitrasi dalam mengolah data calon mempelai. Dengan object oriented methodology menggunakan UML (Unified Modeling Language), peneliti menspesifikasikan objek-objek apa saja yang diperlukan agar sesuai dengan kebutuhan user.
\end{abstract}

Kata Kunci: pendaftaran menikah, website, sistem informasi.

ABSTRACT

KUA (Kantor Urusan Agama) Kecamatan Rajeg already has a website, but it has not used an information system that specifically handles data on marriage registration requirements at KUA. Data inputting and data processing activities still use manual systems. The system is not running optimally because of the complexity of the process, starting from filling in the data on the registration form by prospective brides in the book, processing registration files, to the process of making reports. Reporting constraints occur because the file is not stored in only one part, this causes the administration to experience delays and errors when making reports. After researching and analyzing the problems that exist in the current system, the user needs to be facilitated with a web-based registration information system for marriage requirements to make it easier for prospective brides to obtain information and marriage registration, as well as for the prospective bride administration in processing data. With object oriented methodology using UML (Unified Modeling Language), researchers specify objects that are designed to suit user needs.

Keywords: marriage registration, website, information system.

\section{PENDAHULUAN}

Dalam definisi umum pengertian requirements (persyaratan) ialah merupakan suatu yang perlu atau harus dipenuhi oleh seseorang agar dapat diterima. Sedangkan sistem persyaratan nikah adalah sistem yang menganalisa formulir dokumen, yang dalam hal ini adalah dokumen nikah. Pada dasarnya sistem persyaratan nikah ini dimaksudkan untuk mengajukan syarat-syarat nikah agar dapat mempermudah dalam proses pendaftaran pada saat itu yang akan digunakan 
oleh pihat yang berkepentingan sebagai memenuhi persyaratan nikah. Kantor Urusan Agama (KUA) merupakan instansi urusan agama yang terletak di kecamatan rajeg kabupaten tangerang. KUA (Kantor Urusan Agama) Kecamatan Rajeg sudah memiliki website, tetapi KUA tersebut belum menggunakan sistem informasi yang secara khusus menangani data pendaftaran persyaratan nikah di KUA. Pihak calon mempelai mengalami kendala memperoleh informasi perihal persyaratan pendaftaran. Aktivitas input data dan pengolahan data masih menggunakan sistem manual. Sistem tersebut berjalan tidak optimal karena kompleksitas pada prosesnya, mulai dari pengisian data diformulir pendaftaran oleh calon mempelai dibuku, proses pengolahan berkas-berkas pendaftaran, sampai dengan proses untuk menghasilkan laporan. Hambatan atau kendala saat pembuatan laporan terjadi karena berkas tidak tersimpan di satu bagian saja, akibatnya pihak administrasi mengalami keterlambatan dan mengalami kesalahan saat pembuatan laporan karena berkas yang tersebar.

Kepala KUA pada umumnya memonitoring data persyaratan nikah sampai dengan mengetahui jumlah pasangan yang mendaftarkan nikah pada saat ini. Hal ini sulit terindentifikasi dan memerlukan waktu yang cukup lama dalam pengelolaan data pernikahan. Sehingga disimpulkan permasalahan yang dihadapi, antara lain :

1. Kompleksitas proses pendaftaran nikah. Calon pendaftar harus sering bulak balik untuk mengisi berkas, memenuhi persyaratan nikah, sampai menerima jadwal nikah.

2. Hambatan atau kendala saat pembuatan laporan terjadi karena berkas tidak tersimpan di satu bagian saja, akibatnya pihak administrasi mengalami keterlambatan dan mengalami kesalahan saat pembuatan laporan karena berkas yang tersebar.

3. Penyimpanan data masih menggunakan sistem berkas sehingga mengakibatkan penumpukan berkas, hal ini dapat menyulitkan pencarian data ketika dibutuhkan.

\section{METODE PENELITIAN}

Ada beberapa metode pengumpulan data. Metode tersebut direlevansikan dengan jenis data yang akan dikumpulkan yaitu teknik untuk pengumpulan data primer dan teknik untuk pengumpulan data sekunder.

A. Metode Pengumpulan Data

Pengumpulan data primer pada penelitian ini dilakukan dengan metode survei. Metode survei adalah metode pengumpulan data primer yang menggunakan pertanyaan lisan maupun tulisan dari pihak pengguna yang dalam hal ini adalah petugas KUA dan calon mempelai. Metode ini memerlukan adanya komunikasi langsung antara saya selaku peneliti dengan pengguna sistem (stakeholder). Untuk memperoleh data penelitian terkait kebutuhan sistem, dilakukan melalui wawancara langsung dengan petugas KUA selaku stakeholder di kecamatan rajeg kabupaten tangerang. 


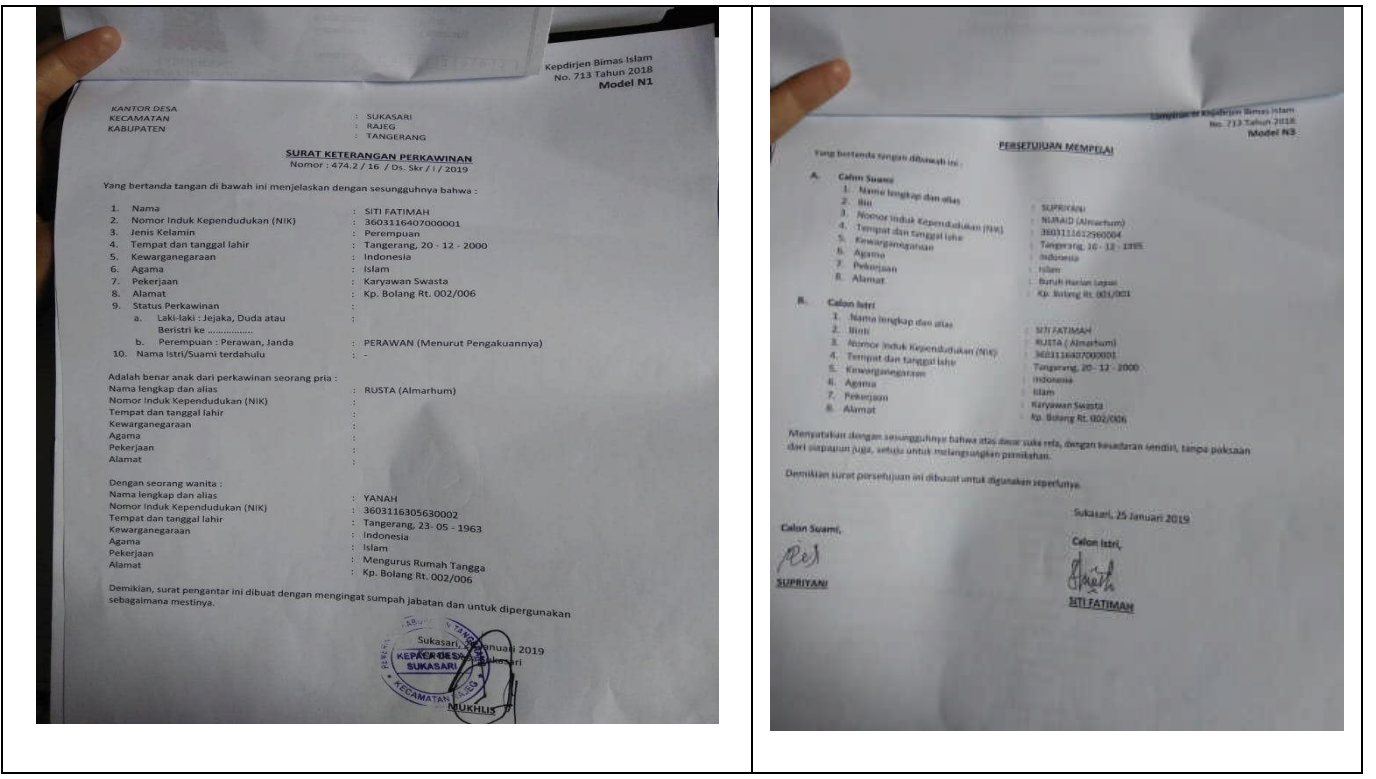

Gambar 1. Berkas persyaratan nikah dan input data nikah

B. Metode Pengumpulan Data

Dalam melakukan pengumpulan data sekunder, peneliti mendapatkannya secara tidak langsung atau melalui media perantara (diperoleh dan dicatat pihak lain) dan data sekunder tersebut merupakan data internal. Data internal merupakan data-data yang ada dan didapat dari organisasi atau perusahaan yang diteliti.

Dari penelitin ini, metode penelitian yang dipakai peneliti dalam melakukan analisa kebutuhan sistem di KUA kecamatan rajeg kabupaten tangerang adalah sebagai berikut :

a. Mempelajari prosedur-prosedur operasional yang berlaku saat pendaftaran nikah di KUA kecamatan rajeg kabupaten tangerang.

b. Mempelajari proses kegiatan pendaftaran nikah, pengolahan data calon mempelai, sampai dengan proses pelaporan hingga terbentuknya buku nikah di KUA kecamatan rajeg kabupaten tangerang.

c. Mempelajari dokumen-dokumen pendukung lainnya di KUA kecamatan rajeg kabupaten tangerang.

d. Mempelajari kekurangan atau kelemahan sistem pendaftaran nikah yang saat ini berjalan di KUA kecamatan rajeg kabupaten tangerang.

e. Membuat rancangan awal (rancangan umum) untuk alur pendaftaran nikah dan pengolahan datanya pada KUA kecamatan rajeg kabupaten tangerang, yang selanjutnya akan dipakai sebagai acuan untuk merancang sistem informasi pendaftaran nikah di KUA kecamatan rajeg kabupaten tangerang.

\section{HASIL \& PEMBAHASAN}

3.1 Sistem Yang Belum Terkomputerisasi.

Proses sistem pendaftaran nikah yang saat ini berjalan di KUA kecamatan rajeg kabupaten tangerang adalah sebagai berikut :

1. Calon pengantin / tamu mencari informasi di KUA kecamatan rajeg kabupaten Tangerang perihal berkas-berkas apa saja yang dibutuhkan untuk mendaftar pernikahan.

2. Lalu calon pengantin / tamu memberikan data persyaratan nikah dari RT dan kelurahan sesuai informasi kepada resepsionis.

3. Resepsionis mengeluarkan formulir pengisian persyaratan nikah kepada calon mempelai.

4. Resepsionis memberikan formulir pengisian persyaratan nikah tersebut kepada Penghulu untuk diverifikasi. 
5. Jika data sudah dianggap valid, berkas-berkas tersebut diarahkan kebagian administrasi, lalu Penghulu membuat penjadwalan nikah.

6. Pihak administrasi memberikan informasi pembayaran biaya nikah.

7. Calon pengantin melakukan transfer pembayaran nikah.

8. Calon pengantin menunjukan tanda bukti transfer ke administrasi.

9. Pemberian jadwal nikah.

10. Administrasi menginput data pembayaran.

11. Penghulu membuat surat keterangan daftar nikah.

Seperti yang tergambar pada use case diagram pada Gambar 1. Proses pengolahan data nikah di KUA kecamatan rajeg kabupaten tangerang adalah sebagai berikut :

1. Semua berkas pendaftaran calon pengantin setiap bulan dikumpulkan kembali, disiapkan untuk pembuatan laporan.

2. Pembuatan laporan pendaftaran nikah yang dibuat secara manual dalam aplikasi sederhana untuk dilaporkan kepada pimpinan Kecamatan.

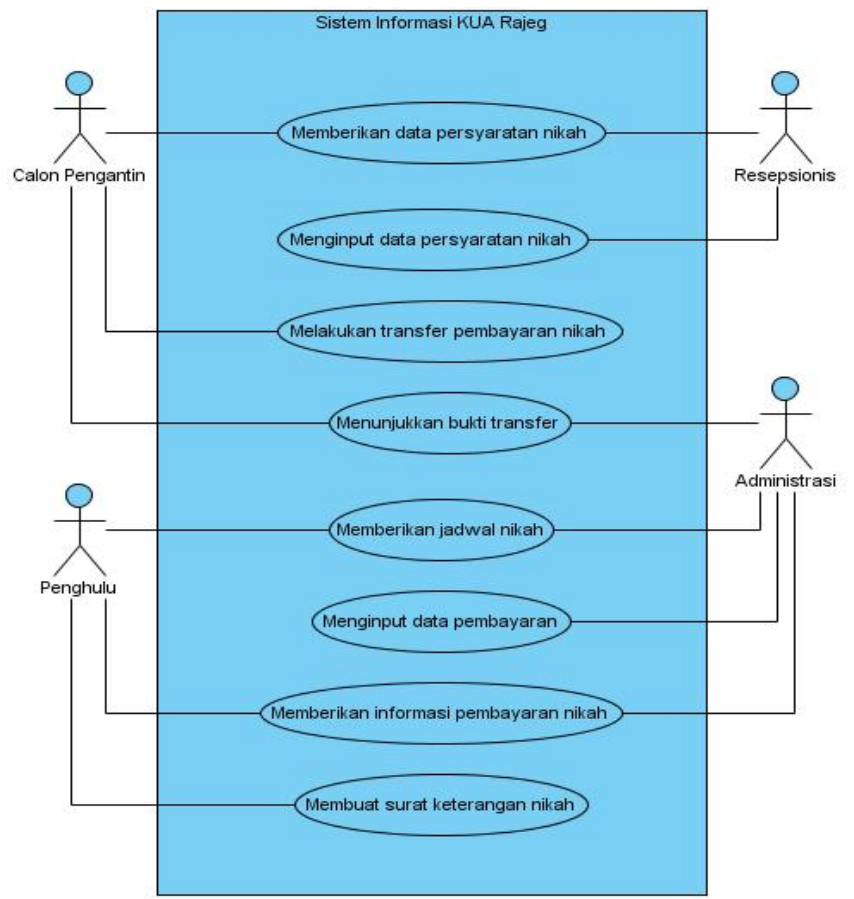

Gambar 2. Use Case Diagram sistem saat ini

\subsubsection{Use Case Diagram Sistem Informasi Pendaftaran Nikah}

Berdasarkan Gambar dibawah, dapat dijelaskan bahwa sistem dirancang untuk memberikan efisiensi kepada pihak calon mempelai maupun pihak petugas KUA. Sistem menyediakan fasilitas halaman pendaftaran nikah, terdapat informasi persyaratan juga yang langsung dapat dibaca oleh calon mempelai untuk dilengkapi, sehingga calon mempelai tidak perlu bulak balik ke KUA. Sistem juga menyediakan fasilitas generate report bagi petugas KUA, sehingga petugas tidak perlu membuat ulang laporan pendaftaran nikah yang sudah di-input sebelumnya oleh calon mempelai setiap bulannya. 


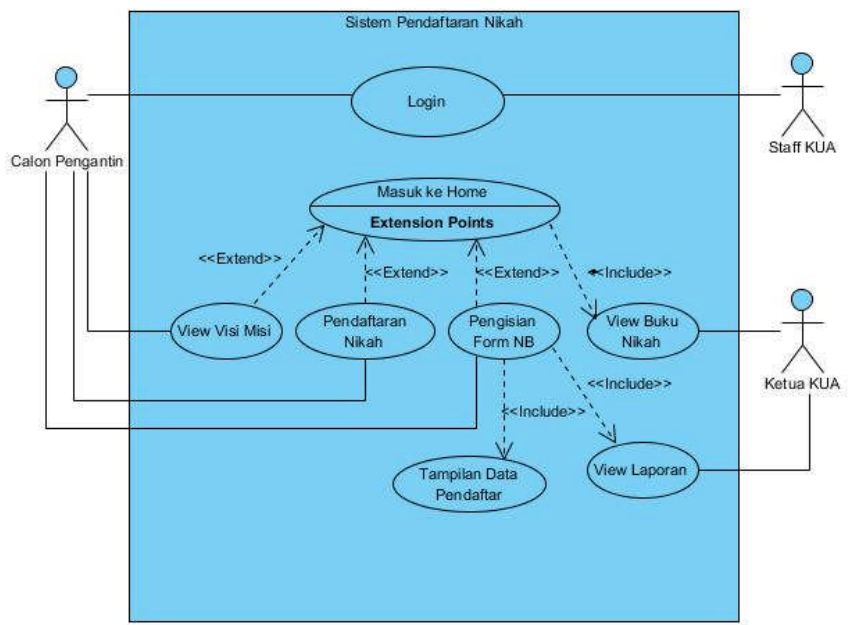

Gambar 3.Use Case Diagram sistem informasi pendaftaran nikah

\subsubsection{Sequence Diagram Sistem Informasi Pendaftaran Nikah}

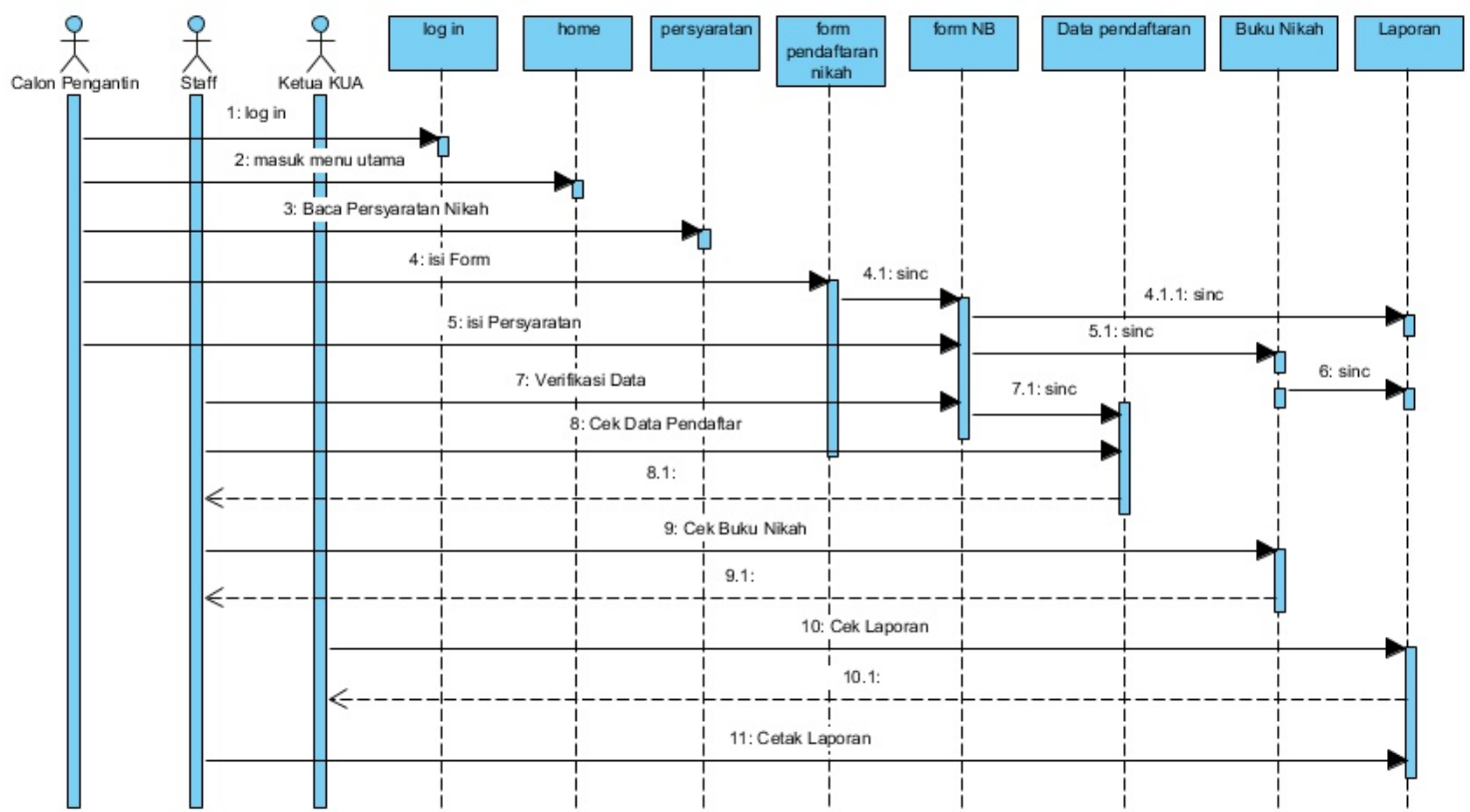

Gambar 4. Sequence Diagram Sistem Informasi Pendaftaran Nikah

Berdasarkan Gambar 4, terdapat beberapa objek yang dibutuhkan user, antara lain halaman informasi Persyaratan nikah, Form Pendaftaran Nikah, Form NB (jadwal nikah), Data Pendaftar keseluruhan, Buku Nikah, sampai dengan display Laporan. Data yang diinput oleh calon mempelai pada halaman Pendaftaran akan tersimpan dalam database, dan akan tampil pada halaman Form NB untuk dilakukan verifikasi oleh staff KUA untuk penjadwalan. Semua data akan secara otomatis disinkronisasikan ke halaman Data Pendaftaran oleh sistem yang berisikan informasi seluruh pendaftar atau calon pemempelai. Database juga meyimpan data untuk diambil kembali saat pembuatan Buku Nikah dan pembuatan Laporan oleh staff KUA, sehingga tidak perlu lagi membuat laporan manual, karena secara otomatis akan ditampilkan pada halaman Laporan.

\subsubsection{Class Diagram Sistem Informasi Pendaftaran Nikah}


Class Diagram juga merupakan rancangan acuan untuk pengambilan data pada basis data dari Sistem Informasi Pendaftaran Nikah pada aplikasi sistemnya.

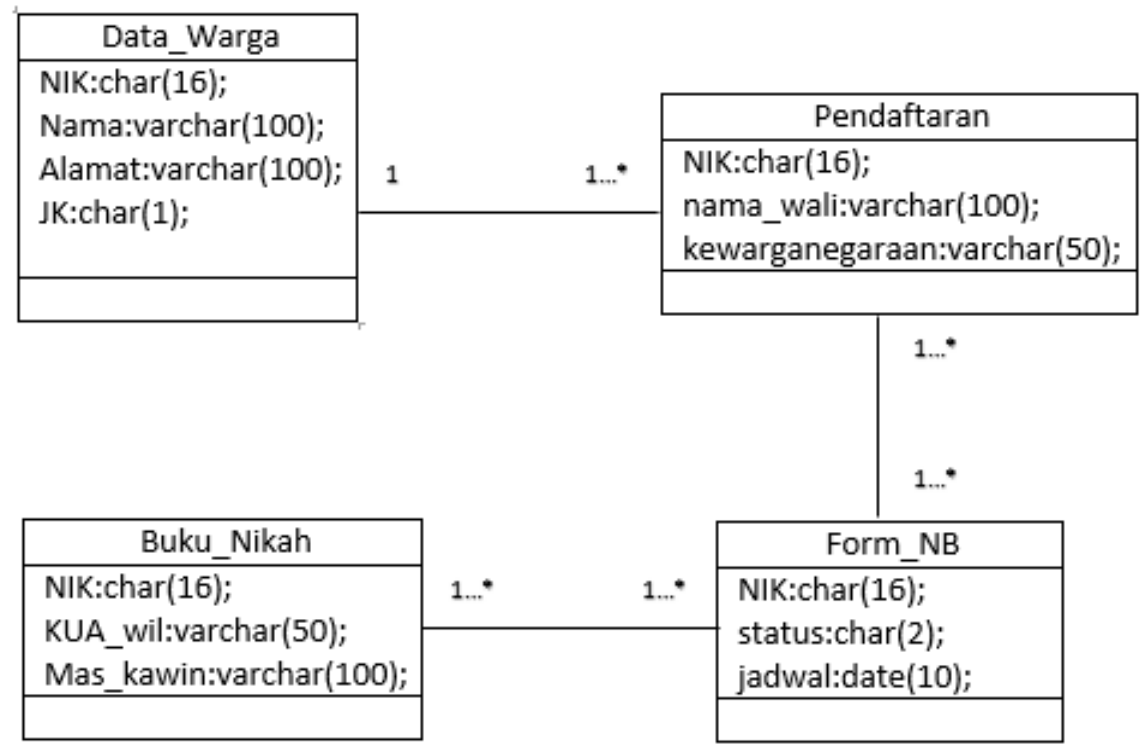

Gambar 5 Class Diagram Sistem Informasi Pendaftaran Nikah

Objek class yang saling berelasi diatas merupakan gambaran pengolahan data pendaftaran nikah. Data yang sudah diinput oleh calon mempelai pada objek Pendaftaran Nikah tersimpan dengan akurat dan dapat di-share, sehingga staff KUA tidak perlu lagi membuat ulang laporan pendaftaran nikah. Objek class Pendaftaran direlasikan dengan objek class Form NB agar data bisa sharing untuk kemudahan melakukan penjadwalan. Untuk objek Data Pendaftar yang menampilkan data keseluruhan pendaftar nikah dapat diambil dari database pada class objek Pendaftaran dan/atau Form_NB. Objek class Form NB direlasikan pula dengan objek class Buku Nikah, yang dilengkapi dengan sejumlah field yang lain untuk melengkapi data yang sesuai dengan ketentuan buku nikah seperti mas kawin, dll.

\section{IMPLEMENTASI}

4.1 Rancangan Aplikasi

Dalam rancangan sistem informasi pendaftaran persyaratan nikah, peneliti membuat rancangan aplikasi yang sesuai dengan kebutuhan masyarakat dan staff KUA.

a. Halaman Utama

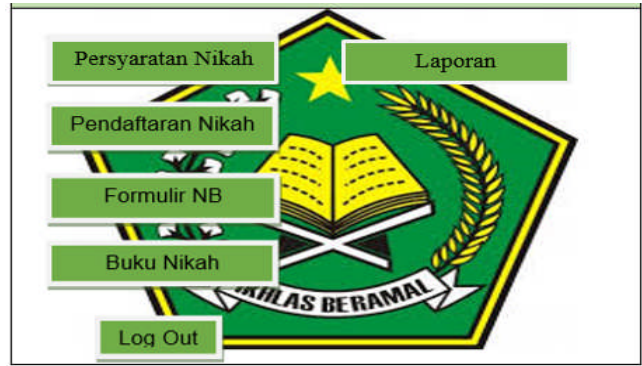

Gambar 6 Tampilan Halaman Utama

Gambar 6 diatas merupakan tampilan utama yang digunakan oleh user jika memasuki sistem informasi pendaftaran persyaratan nikah pada KUA Kec.Rajeg. Terdapat pilihan halaman untuk mendapatkan informasi terkait pendaftaran nikah bagi masyarakat. 


\section{b. Halaman Form Pendaftaran Nikah}

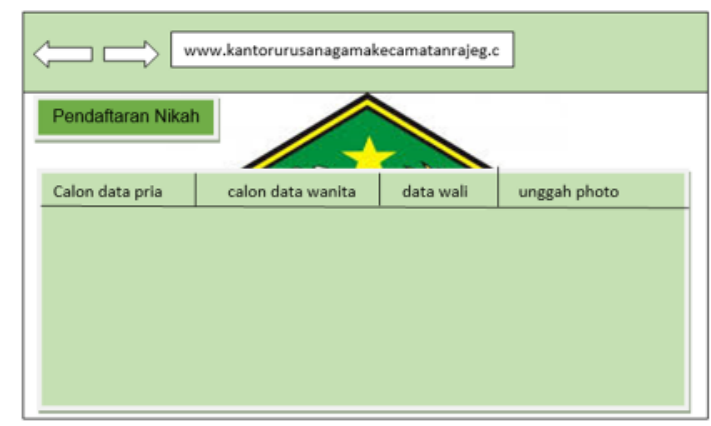

Gambar 7 Tampilan Form Pendaftaran Nikah

Gambar 7 merupakan tampilan untuk pendaftaran nikah yang digunakan oleh calon mempelai jika memasuki sistem informasi pendaftaran persyaratan nikah pada KUA Kec.Rajeg. Dengan mengisi data calon mempelai pria, calon mempelai wanita, data wali calon mempelai, beserta kelengkapan foto.

\section{c. Halaman Form NB}

Pada Gambar 8 merupakan tampilan form NB yang digunakan oleh staff KUA jika memasuki sistem informasi pendaftaran persyaratan nikah pada KUA Kec.Rajeg. Dihalaman inilah staff KUA melakukan verifikasi kelengkapan data calon mempelai. Jika sudah dinyatakan lengkap, maka penentuan jadwal pernikahan yang tersedia.

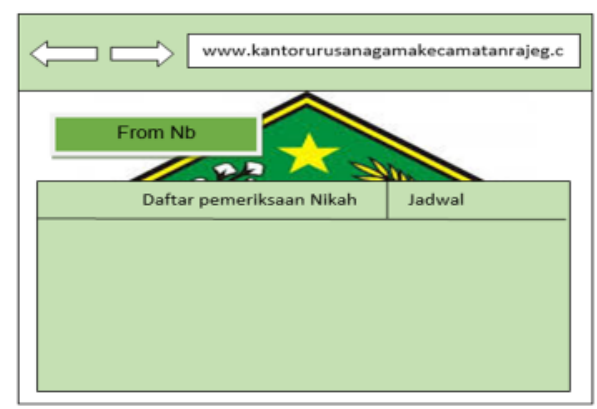

Gambar 8 Tampilan form NB

d. Rancangan Buku Nikah

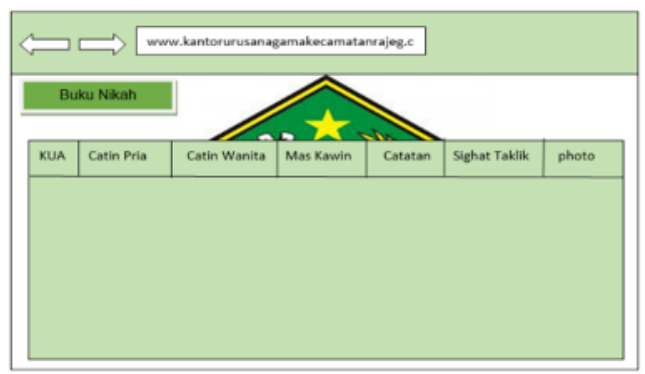

Gambar 9 Tampilan data buku nikah

Pada Gambar 9 merupakan tampilan buku nikah yang digunakan oleh staff KUA jika memasuki sistem informasi pendaftaran persyaratan nikah pada KUA Kec. Rajeg pada menu Buku Nikah. Data master sudah diintegrasikan, sehingga staff hanya mengisi data lain untuk melengkapi data Buku Nikah ini. 


\section{KESIMPULAN}

Setelah meneliti dan menganalisa permasalahan yang ada dalam sistem saat ini, user perlu difasilitasi sebuah sistem informasi pendaftaran persyaratan nikah berbasis web untuk mempermudah calon mempelai dan juga bagi pihak staff KUA Kecamatan Rajeg, sistem memberi kemudahan bagi pihak instansi dalam aktivitas pengolahan data calon mempelai.

a. Sistem memberikan informasi pendaftaran nikah, sehingga calon pengantin tidak harus harus bolak balik ke kantor KUA.

b. Sistem mempermudah pendaftaran nikah calon mempelai melalui website, sehingga calon mempelai dapat mendaftar nikah kapanpun dan dimanapun melalui aplikasi web yang disiapkan.

c. Pihak staff KUA Kecamatan Rajeg tidak perlu menyediakan banyak kertas untuk pengisian formulir, karena aplikasi sistem sudah tersedia halaman untuk input data calon mempelai dan data akan tersimpan dengan baik dalam database.

d. Proses pengelolaan dokumen persyaratan nikah dikantor urusan agama pada kecamatan rajeg menjadi lebih singkat dan efektif, Penghulu tidak perlu lagi melakukan pencatatan dibuku induk penghulu, serta membuat laporan, database yang akan mengelola data tersebut. Data yang di-input oleh calon mempelai dapat dilihat langsung oleh Penghulu, Penghulu dapat menerima langsung laporan semua data calon mempelai melalui halaman aplikasi sistem.

\section{DAFTAR PUSTAKA}

[1] Azizah, Nur, dkk. (2017). Perancangan Sistem Informasi Penilaian KINERJA KARYAWAN SPG BERSTATUS KONTRAK PADA PT. SOFTEX INDONESIA MENGGUNAKAN METODE SIMPLE ADDITIVE WEIGHTING (SAW). Journal SENSI, Vol.3, No.2. http://ejournal.raharja.ac.id/index.php/sensi/article/view/664

[2] Aryani, D., Nurdin, M. A., \& Baskara, P. (2017). SISTEM INFORMASI PENGELOLAAN ASET KENDARAAN BERMOTOR PADA STMIK RAHARJA TANGERANG. CERITA Journal, 3(1), 7584.

[3] Cahyanti, A.N., \& Purnama, B. E. (2017). Pembangunan Sistem Informasi Manajemen Puskesmas Pakis Baru Nawangan. Speed-Sentra Penelitian Engineering dan Edukasi, 4(4).

[4] Hutahaean, J. (2015). Konsep sistem informasi. Deepublish.

[5] Muslihudin, M. (2016). Analisis dan Perancangan Sistem Informasi Menggunkan Model Terstruktur dan UML. Penerbit Andi

[6] Rabitha, D. (2015). Penyelenggaraan Kursus Pra Nikah di Kabupaten Purwakarta: Kasus KUA Purwakarta, Cibatu, dan Babakan Cikao. Penamas, 28(3), 505-524.

[7] Sunarya, A., Aisyah, E. S. N., \& Amelia, K. R. (2018). Aplikasi Sistem Pengendalian Internal Terhadap Piutang Pada PT. Mitra Toyotaka Indonesia. Konferensi Nasional Sistem Informasi (KNSI) 2018 . 